\title{
Root canal overfilling as an influencing factor for the success of endodontic treatment
}

\author{
Ardo Sabir \\ Department of Conservative Dentistry \\ Faculty of Dentistry Hasanuddin University \\ Makassar - Indonesia
}

\begin{abstract}
The goal of endodontic treatment is to keep the teeth as long as possible in the mouth. The obturation process in the root canal is one of the most important processes in endodontic treatment. The purpose of this article is to explain that overfilling is an influencing factor to the success of endodontic treatment. It has been widely known that overfilling should be avoided during an obturation process. Overfilling of the root canal is indicated only in cases which will be followed by apicoectomy, when the foreign material is removed. Accidental overfilling may occur with soft material (for example, certain pastes and cements) or with solid material (such as gutta-percha or silver cones). Such overfilling may cause an unnecessary mechanical and chemical irritation, which hinders the repair of periapical tissue, and thus, diminishes the probability of a successful endodontic treatment prognosis. Many things could cause overfilling, which makes overfilling unpleasant feeling for the patient such as severe pain, periapical lesion, gingival discoloration, periodontal ligament breakage, or even paresthesia. There are several ways to overcome this root canal overfilling, from the conventional endodontic treatment up to endodontic surgery. The main conclusion from this article is to avoid overfilling and the importance of clinicians' compliance to the right procedures.
\end{abstract}

Key words: overfilling, endodontic treatment

Correspondence: Ardo Sabir, c/o: Bagian Konservasi Gigi, Fakultas Kedokteran Gigi Universitas Hasanuddin. Jln. Kandea 5 Makassar, Indonesia.

\section{INTRODUCTION}

The general purpose of endodontic treatment is to maintain teeth duration as long as possible in the mouth cavity. The treatment undergoes three stages: the pulp space biomechanic preparation, root canal sterilization, and root canal filling. 1,2

The root canal filling can not be hindered if the stage prior to filling is done correctly and adequately. ${ }^{1}$ The purpose of root canal filling is to fill up or block all root canal and to form a fluid-tight seal on the apical foramen of the tooth, so that any possibility of a secondary infection occurrence due to the mouth cavity or periradicular tissue leakage into the root canal system can be avoided. $1,3,4$ Clinically, the success of an endodontic treatment can be determined byan X-ray photo, clinical sign and/or symptom, histologic and immunopathologic examinations. ${ }^{5-7}$ Ideally, the root canal filling stage has to achieve a hermetic filling which is the crucial stage to obtain a successful endodontic treatment. ${ }^{2}$

It is frequent to find accidents of endodontic treatment failure due to bacterial infection or because of wrong procedures during endodontic treatment process. ${ }^{6,8,9}$ The mistake can be classified into two natures. ${ }^{2,6,10}$ The first mistake is inadequate arsenic use during tooth pulp devitalization, that cause a gingival necrosis or periodontitis. The necrotic gingival after arsenic use is caused by the lost of temporary filling substance. The periodontitis is, infact, influenced by excessive arsenic use, where the arsen is too long inside the tooth. The second mistake is a complication during endodontic treatment process, a perforation in bifurcation area or trifurcation of the posterior tooth during root canal exploration, root canal broken instrument, or an overextension of filling substance overpassing the apical foramen (overfilling).

If overfilling occurs, two filling incidents may happen i.e. root canal solidly filled or unsolidly filled conditions by filling substance. ${ }^{11}$ According to Ingle et al., ${ }^{1} 60 \%$ of endodontic treatment failure iscaused by the failure of root canal filling . Furthermore Grossman et al. ${ }^{2}$ state that endodontic treatment failure is due to non-hermetic filling up to $67 \%$.

The aim of this article is to give information about the cause of overfilling and the involved consequences, the way to manage overfilling, and all precautions to prevent overfilling.

\section{Overfilling cause and effect}

It is already known that the success rate of endodontic treatments decreases when overfilling occurs. There are several factors to cause overfilling: too much cement in the root canal, unprecise working length measurement, no $\mathrm{X}$-ray photo prior, during, and after the treatment process, over-instrumentation, excessive pressing to filling 
substance, resistency disappearance due to inadequate root canal preparation, the use of injection technique to fill the root canal, improper apical seal and operator's lack of skill. $1,2,9,12$

The effect of overfilling is varied, determined by ${ }^{13}$ the type of filling substance, filling substance's quantity which passes the apical foramen, and how far the filling substance surpasses the apical foramen. Based on these three factors, the most common effects of overfilling are inflammation reaction of the periapical tissue causing severe pain accompanied by swollen tissue, periodontal ligament breakage, and a periapical lesion.2,13,15 Other effects are necrosis of alveolar bone in the periapical area of the discoloration mucosa membrane covering tooth apex, or even a neurological complication such as paresthesia.

\section{Managing overfilling}

There are several alternatives to overcome overfilling during an endodontic treatment. They are by taking no treatment, conventional endodontic treatment, or performing an endodontic surgery. $2,3,6,14$

In specific overfilling cases, one can do no correction measure depending upon the used type of filling substance and how far the filling substance overpasses the apical foramen. Should the filling substance be biocompatible, e.g. gutta percha or titanium cones, and it does not pass the apical foramen more than $1 \mathrm{~mm}$, no action or correction measures needed. The same approach is applied if the filling substance can be re-absorbed by our body in the form of paste or cement form substance (Figure 1). 3,6,10,11,14,16

If the filling substance which passes the apical foramen cannot be re-absorbed, or it is biocompatible but it passes the apical foramen not more than $1 \mathrm{~mm}$, the conservative measure such as a conventional endodontic treatment is applicable.2,3,10,16 This treatment consists of X-ray photo of the overfilled tooth and expelling all filling substance from the root canal. If the filling substance is a gutta percha cone, one can use a root canal spreader, $\mathrm{K}$ type file, or a
Hedstroem type file. But if the guttapercha cone is still difficult to take out, one can help by giving chloroform in the root canal. 2,17,18 The filling substance in the form of silver or titanium cones can be taken out from the root canal using a pincet or a hemostat,3,16 whereas for filling substance from paste or cement, one can use a reamer or $\mathrm{K}$ type file. ${ }^{10,18}$ Consecutively, a root canal re-preparation with precise and adequate procedures must be done. It is then followed by re-filling the root canal using a new filling substance, and the last measure is an X-ray photo to see the precision of the filling. 2,3,7,10,16

Overfilling management can be done by performing an endodontic surgery. This is a radical measure to be chosen as operator's last choice whenever the conservative treatment has fails. There are two indicators of conventional endodontic treatment failure. Those are non-vanishable or heavier symptom on patients and operator's failure to expel the filling substance irritating root canal's periapical tissue. ${ }^{10}$ The endodontic surgery can be a curettage (apicocurettage) or apicoectomy. Apicocurettage is a measure to take out tissues at the apical area, and apicoectomy is a surgery measure to cut dental apex and take out some surrounding tissue. The root canal filling can be done before or right after the dental apex is cut, or before or right after the dental apex is cut (Figure 2).2,3,10

\section{Preventing overfilling}

To prevent an overfilling during endodontic treatment, operators should take cautious actions by emphasizing several matters, such as work with lege artis attitude during treatment process including calculating worklength precisely, proper usage of intracanal apparatus, maintaining resistency form during the root canal preparation, no excessive pressure towards intracanal tool during the preparation process and towards filling substance during root canal filling, as well as utilizing sealer only as much as it is needed. Morerover, the applicated sealer must have a minimal toxicity level to prevent more damage when an

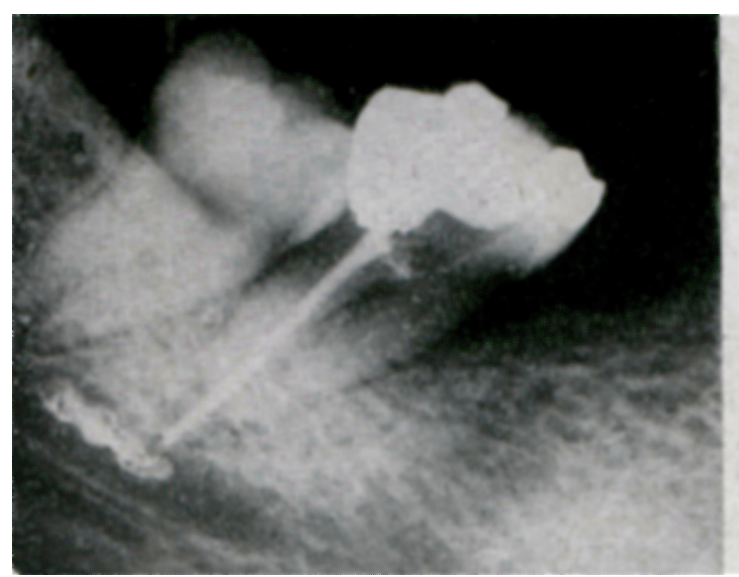

A

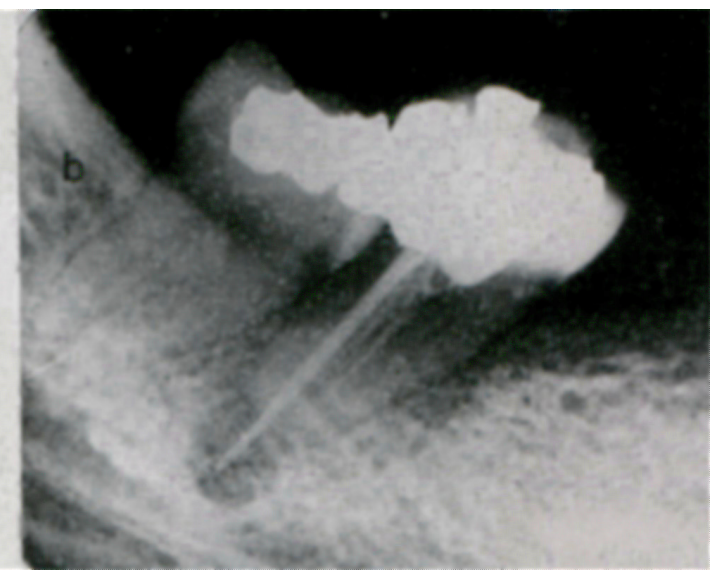

B

Figure 1. An X-ray photo of overfilling with paste form filling substance: zinc oxide eugenol, inflicting severe pain to patients. A) Immediately after an endodontic reatment; B) One year after overfilling, 50\% resorption of zinc oxide eugenol took place. ${ }^{14}$ 


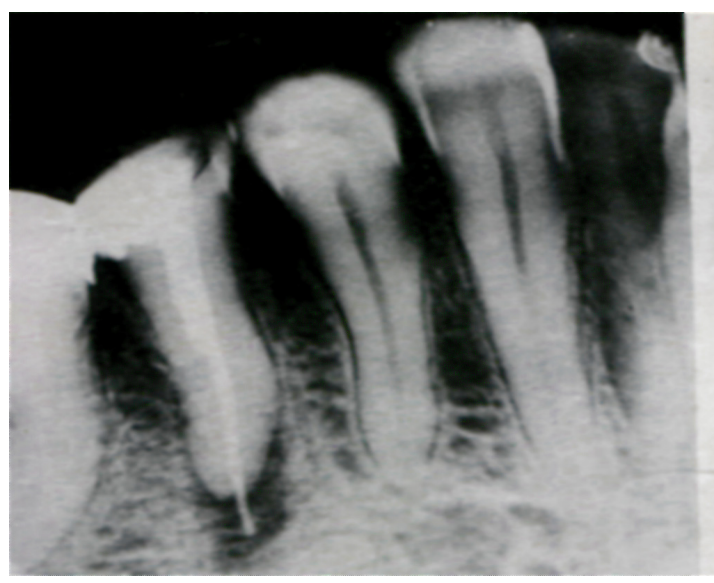

A

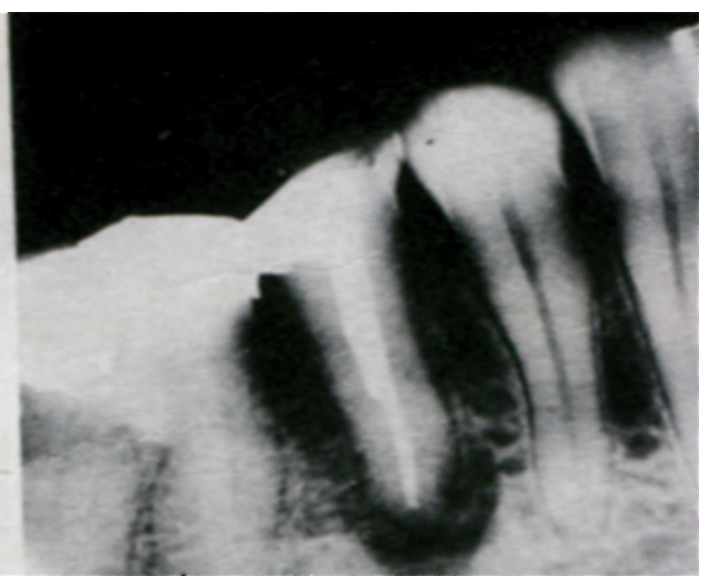

B

Figure 2. An X-ray photo of overfilling with gutta percha cone in the second premolar of the lower jaw, causing abscess and paresthesia. A) Immediately after an endodontic treatment; B) After apicoectomy. ${ }^{14}$

overfilling occurs. The use of a filling substance containing formaldehyde or paraformaldehyde should be avoided because this substance can produce damaging effects to the patient. Endodontic treatment of the first molar distal dental root, and on both mandibles, as well as the dental root of premolar both mandibles should be carefully done because the anatomical form of those roots are close to Canalis mandibula. The operator should be careful to choose a filling substance from paste texture, because it is really difficult to control while pouring it to the root canal.

\section{DISCUSSION}

The occurrence of overfilling caused by a filling substance with a soft constancy/texture such as paste or cement e.g. paraformaldehyde, AH26, Hydron, Diaket-A and zync oxide eugenol or a solid constancy such as gutta percha or silver cones can present bad reactions/effects to patients. Sometimes, the reaction is minor or in light signs such as temporary inflammation, but eventually it can also give damaging effects of overfilling, by unavoidably deforming the surrounding tissue permanently. ${ }^{13}$

Tschamer cit. Kaufman and Rosenberg 19 found a periodontal ligament damage as an effect of overfilling using root canal filling substance containing paraformaldehyde. On the other hand, Heling et al. and Tal et al. cit Kaufman and Rosenberg ${ }^{19}$ reported several cases with alveolar bone necrosis as a result of overfilling with sealer containing paraformaldehyde (Endomethasone (B). Numerous writers also found serious damages in the periapical tissue including nerve fibers due to $\mathrm{N}_{2} \cdot{ }^{20,21}$

Several writers have reported overfilling cases from AH-26 substance and zinc oxide eugenol resulting inflammation reactions on patients. ${ }^{14,22,23}$ Lindner $^{24}$ found an incident of overfilling from Diaket-A substance producing severe pain of overfilling area, followed by paresthesia five days post overfilling.
Some other writers reported that two important mechanisms were responsible for the nerve fibers damage after an overfilling causing paresthesia. The first mechanism was a chemical neurotoxic as a result of either one or more components of overfilling substance. The second mechanism was a damage and degenerated nerve fibers due to a mechanical effect after the pressed or smashed filling substance. It was then pushed to Canalis mandibula. ${ }^{13,14}$

Brodin et al. ${ }^{25}$ described quite a few overfilling cases with $\mathrm{N}_{2}$ or paraformaldehyde containing filling substance which displayed strong neurotoxic activity to generate permanent nerve damages. While several other writers wrote about the appearance of paresthesia of interior alveolaris nerves and a long stinging pain caused by root canal cement with paraformaldehyde. ${ }^{19,21}$ If the root canal filling substance $\left(\mathrm{N}_{2}\right.$ or paraformaldehyde) makes overfilling, a quickest possible radical measure must be performed (endodontic surgery) to prevent the occurrence of nerve injury, since a nerve damage has no restoring process. ${ }^{13}$

It was reported that if a contact was established between phenol (or its derivatives) and the nerve for several weeks period, a permanent nerve damage would occurr. ${ }^{26}$ Even if a healing process happened later, it would take a long period of time. ${ }^{14,26}$ Besides, the healing process could take place only if the scarred tissue of the nerves did not obstruct the regeneration process of nerve fibers. ${ }^{13}$ Eugenol is a phenol derivate used for a long duration of time in the dentistry world. It has a local anesthetic effect and is able to penetrate tissues yielding protein coagulation. With enough concentration, eugenol's ability to coagulate protein can generate permanent nerve damage if the contact happens for several weeks. ${ }^{13,26}$ Yet, it was reported that a spontaneous nerve healing process occured in 4-12 months in several cases of overfilling with eugenol contained filling substance. ${ }^{14,27}$ 
The nerve fibers damage is categorized into three types. The first one is a direct damage to the nerves. The second is a direct pressure from the filling substance and the last one is an indirect pressure. ${ }^{14}$ The direct damage to the nerves can be caused by gutta percha or silver cone overfilling. Although these two substances are non-toxic, ${ }^{28}$ the human body itself can react with a rejection as a defence mechanism towards foreign substances. If this happens, the overfilling filling substance must directly be expelled to stop nerve irritation.

The damage is caused by direct pressure from the overfilling filling substance e.g.AH-26 or Diaket-A which has the capacity to spread and occupy spaces surrounding the nerves. This damage can be predicted by measuring the volume of the overfilling substance and human body's ability to re-absorb the foreign material. If the volume is too high, it can generate nerve or blood vessel strangulation. Even so, if the human body can re-absorb, nerve damage will not happen. Should the operator find this condition, it would be best to lay off any action for the first month, unless there were complaints. Then, a conservative measure in the form of conventional endodontic treatment can be applied.

A nerve damage originated from an indirect mechanical pressure to the nerves can be caused by hematomes or edema which is a part of the inflammation stage of the wound healing. The longer the inflammation stage takes place, the more possible to have a complication in the form of scarred tissue resulting in permanent impairment nerve fibers or blood vessels. ${ }^{14}$ Based on the explanation above, it can be concluded that the chemical neurotoxic factor of the overfilling filling substi...ce is more influential to nerve damage (paresthesia) than the mechanical factor. ${ }^{25}$

From the article, the researcher draws conclusions that overfilling is one of local factors to produce an endodontic treatment failure. Apart from the skill of the operator, overfilling can also caused by lack of standard treatment procedure. Overfilling can show light sign up to heavy symptoms inflicting painful sufferings to patients. If a sign or complaint occurs, patient must be given a conservative measure in the form of conventional endodontic treatment, and if necessary a radical measure as endodontic surgery. The prognosis of an overfilling tooth very much depends on the toxicity level and the amount/volume of the overfilling substance, and how fast the human body can re-absorb that filling substance.

\section{REFERENCES}

1. Ingle JI, Newton CW, West ID, et al. Obturation of the radicular space. In: Ingle JI, Bakla: LK, editors. Endodontics. $5^{\text {th }}$ ed. Hamilton: BC Decker Inc; 2002. p. 571-4.

2. Grossman LI, Oliet S, Del Río CE. Endodontic practice. $11^{\text {th }}$ ed. Philadelphia: Lea and Febiger; 1988. p. 179.
3. Dummer PMH. Root canal filling. In: Ford TRP, editor. Harty's endodontics in clinical practice. $5^{\text {th }}$ ed. Edinburgh: Wright; 2004. p. 113.

4. Sjörgen U, Hagglund B, Sundqvist G, Wing K. Factors affecting the long-term results of endodontic treatment. J Endod 1990; 16:498-504.

5. Frank AL, Simon JHS, Abou-Rass M, Glick DH. Clinical and surgical endodontics concepts in practice. Philadelphia: JB Lippincott; 1983. p. 88.

6. Manisali Y, Yücel T, Eri•en R. Overfilling of the root. Oral Surg Oral Med Oral Path. 1989; 68(4):773-5.

7. Selden HS. The endo-antral syndrome: An endodontic complication. J Am Dent Assoc 1989; 119:397-402.

8. Lin LM, Skribner JE, Gaengler P. Factors associated with endodontic treatment failures. J Endod 1992; 18(12):625-7.

9. Siqueira Jr JF. Aetiology of root canal treatment failure: why welltreated teeth can fail. Int Endod J 2001; 34:1-10.

10. Frank RJ. Endodontic mishaps: their detection, correction, and prevention. In: Ingle JI, Bakland LK, editor. Endodontics. $5^{\text {th }}$ ed. Hamilton: BC Decker Inc; 2002. p. 769-89.

11. Bence R. 1976. Buku pedoman endodontik klinik. Sundoro EH. Jakarta: UI-Press; 1990. h. 199-200.

12. Siswadi YLS. Pengisian saluran akar, masalah dan penanggulangannya. Majalah Ilmiah Kedokteran Gigi FKG Usakti 2001; 16(46):181-6.

13. Neaverth EJ. Disabling complications following inadvertent overextension of a root canal filling material. J Endod 1989; 15(3):135-9.

14. Nitzan DW, Stabholz A, Azaz B. Concepts of accidental overfilling and over instrumentation in the mandibular canal during root canal treatment. J Endod 1983; 9(2):81-5.

15. Yaltirik M, Berberoglu HK, Koray M, Dulger O, Yildirim S, Aydil BA. Orbital pain and headache secondary to overfilling of a root canal. J Endod 2003; 29(11):771-2.

16. Nicholls E. Endodontics. $3^{\text {th }}$ ed. Bristol: Wright; 1984. p. 123, 17981.

17. Gerstein H. Techniques in clinical endodontics. Philadelphia: WB Saunders Co; 1983. p. 259-310.

18. Seltzer S. Endodontology biologic considerations in endodontic procedures. $2^{\text {nd }}$ ed. Philadelphia: Lea and Febiger; 1988. p. 44853.

19. Kaufman AY, Rosenberg L. Paresthesia caused by endomethasone. J Endod 1980; 6(4):529-31.

20. Montgomery S. Paresthesia following endodontic treatment. J Endod 1976; 2:345-7.

21. Grossman LI. Paresthesia from $\mathrm{N}_{2}$ or $\mathrm{N}_{2}$ substitute. Oral Surg Oral Med Oral Path. 1978; 45(1):114-5.

22. Speilman A, Gutman D, Laufer D. Anesthesia following endodontic overfilling with AH-26. Oral Surg Oral Med Oral Path 1981; 52:554-6.

23. Tamse A, Kaffe I, Littner MM, Kozlovsky A. Paresthesia following overextension of AH-26: report of two cases and review of the literature. J Endod 1982; 8:88-90.

24. Lindner G. Irritation of mental nerve after root canal therapy on the left mandibular second premolar. Quintessence Int 1972; 3:312 .

25. Brodin P, Roed A, Aars H, Orstavek D. Neurotoxic effects of rootfilling materials on rat phrenic nerve in vitro. J Dent Res 1982; 61:1020-3.

26. Formin GH, Rood JP. Successful retrieval of endodontic material from the inferior alveolar nerve. J Dent Res 1977; 5:47-50.

27. Ørstavik D, Brodin P, Ass E. Paresthesia following endodontic treatment: Survey of the literature and report of a case. Int Endod J $1983 ; 16: 167-72$.

28. Spangberg L, Lan sland K. Biologic effects of dental materials. Toxicity of root canal filling materials on HeLa cells in vitro. Oral Surg Oral Med Oral Path 1973; 35: 402-14. 